\title{
Research on Knowledge Elements of Independent Innovation of Enterprises
}

\author{
Gang Li \\ Hubei Communications Technical College, Wuhan, Hubei Province, China \\ 761615801@qq.com
}

\begin{abstract}
Keywords: Knowledge elements; Independent innovation; Knowledge management; Enterprise innovation
\end{abstract}

\begin{abstract}
This paper summarizes the research direction and current status of teachers in colleges and universities in recent years in the field of human resources, found mainly in three aspects: teachers of university human resource allocation, management, development, the establishment of incentive mechanism and risk analysis; definition, value, value of human capital property rights of university teachers; teachers in colleges and universities human resource value measurement and the distribution of income, personal income and cost of investment in higher education. On this basis, this paper analyzes the existing problems in the research of human resource input and output efficiency of university teachers, and puts forward that the future research direction should focus on the comparison of college Teachers' professional superiority.
\end{abstract}

\section{Introduction}

The core competitiveness of the enterprise comes from the knowledge owned by the enterprise, which includes the ability to discover market and identify market opportunities, develop new products to meet the market demand, integrate the individual into the new product, and push the knowledge products produced by the enterprise to the market. The ability to disseminate knowledge. That is to say, knowledge is the source of the core competitive advantage of an enterprise. The existing knowledge stock of the enterprise determines the ability of the enterprise to find the market and the allocation of resources. The degree of the efficiency of the enterprise resources is closely related to the knowledge owned by the enterprise. Knowledge is the foundation of creating the core competitive advantage of an enterprise. In a sense, modern enterprise management is knowledge management, and enterprise management first is knowledge management. Enterprise management is to create a knowledge management environment, including the establishment of the enterprise culture and the corresponding incentive mechanism for knowledge management, promote the transformation of individual knowledge to organizational knowledge, and translate these knowledge into products and services effectively. Knowledge will become a key factor in creating and consolidating enterprises' continuous innovation capability.

Therefore, in this context, it is of great significance not only to improve the competitiveness of enterprises, but also to improve the ability of independent innovation and the overall innovation ability of the country. On the one hand, we can explore the composition, operation and function of the dynamic mechanism of independent innovation of enterprises. On the other hand, it also marks the organic integration of knowledge management and independent innovation power mechanism. It has a very important and far-reaching significance to encourage and promote the development of enterprises' independent innovation.

\section{Explicit Knowledge Elements}

Knowledge recognition ability. Knowledge recognition ability refers to the awareness ability of enterprise employees in the formation stage of independent innovation conception, research and development stage, pilot stage, batch production stage, marketing stage, innovation technology diffusion 
stage. Knowledge recognition is mainly embodied in the recognition of the enterprise employees' knowledge and knowledge of the enterprise. The basic beliefs and values of the staff and soil determine the independent innovation atmosphere of the enterprise, the behavior of employees' cooperation, competition, coordination and so on, and the knowledge of ethics, ethics, order, the rules, standards and standards of evaluation. The level of independent innovation performance shows that knowledge recognition ability is very important in the process of independent innovation.

Knowledge recognition provides a flexible way for managers to adjust difficulties in the process of independent innovation in complex and changeable enterprises. As the main decision maker of independent innovation, managers need to provide a unified self-concept for the employees, and the ability of knowledge recognition can make use of the internal knowledge communication channels of enterprises to help employees establish organizational identification, promote their understanding of independent innovation, and avoid bringing their employees due to themselves. The sense of alienation induced by the main innovation reduces the psychological burden of employees and improves the success rate of independent innovation. Knowledge recognition ability is a kind of knowledge identity that is designed to achieve the combination of enterprise independent innovation and employee relationship, and contributes to the common development of enterprises and their employees.

New market knowledge. The knowledge of the new market is the technical knowledge of basic research, application research and Development Research of enterprise related products. The knowledge involved in different research links has the intrinsic motivation to the development of production and commercialization.

Knowledge in the new market has brought great changes to enterprises: realizing the independent innovation of basic management, research and development according to the requirements of enterprises' independent innovation. With the help of enterprise resource planning, computer integrated manufacturing system, computer aided design and other technologies, we can deepen the understanding of the new knowledge in the market, make the enterprises R \& D, production, supply, marketing, service and other departments can carry out independent innovation and optimize the enterprise innovation resources.

The new market knowledge includes the production and application of products, the establishment and management of brand and reputation, the acquisition and management of customer resources, the design and management of the sales network, and the development and maintenance of social relations (such as with the government, suppliers, related enterprises and so on). Knowledge in new markets exists in core technologies, key employees and sales channels. Knowledge of the new market is a process of knowledge management for the purpose of opening new markets, such as developing new technologies, exploring new uses of products, obtaining new customers and subdividing the market, and so on. A series of knowledge activities, such as association, recognition, interaction, sharing, integration and activation, will be carried out to maximize the overall benefit of the enterprise from learning, using and creating knowledge through the independent innovation of knowledge and behavior subject.

Expert skills. Expert skills are the embodiment of experts' comprehensive ability to establish and manage enterprises. Experts have formed their own unique knowledge and skills in the process of participating in independent innovation, which affect the smooth progress of enterprise's independent innovation in the future. The experts should have the knowledge and skills that introduce information, automation, digitalization and flexibility into the enterprise, make the enterprise radiant and energetic, and can respond quickly to the changeable market demand. In this way, the enterprise can make less detours in the process of independent innovation and gain more excess profit.

In the normal distribution of skills, only a small number of talents with a skill level higher than the average of 2-3 standard deviations can be defined as skill expertise, and expert skills can make it exceed the general limit of the general staff for information processing, so that the operation tasks that require innovative and complex decision-making can be completed quickly and efficiently. For different tasks, the limits of information processing are also different. With the continuous improvement of expert skills, the enterprise's independent innovation behavior plan is more accurate, and innovative activities are kept in an efficient and stable operation. In addition, expert skills enable independent innovation to be flexible and adapt to complex and changeable environment. 
Management knowledge. Management knowledge refers to the knowledge of a series of work such as decision making, organizing, controlling and coordinating the entire production and management activities of the enterprise, and encouraging the members of the enterprise to achieve their tasks and goals. Management knowledge is an important foundation for enterprises to gain competitive advantages and has become a scarce asset of enterprises. In the dynamic and uncertain environment, the speed of knowledge renewal is quickening. Learning enterprise management strategy, decision and plan, enterprise production and operation management, marketing management, quality management, financial management and human resource management have become the root guarantee for the enterprise to survive. Management knowledge has become the key knowledge element in the enterprise's independent innovation system.

There are many contents in the management of enterprises, which involve the management of the supply, production and sale of raw materials. In the era of knowledge economy, knowledge capital has penetrated into all aspects of enterprise management, such as production, R \& D and sales. The more knowledge and knowledge of business management, the higher the conversion rate and utilization rate of knowledge capital, and the stronger the independent innovation capability of enterprises. Therefore, management knowledge is mainly dependent on the accumulated experience of employees after continuous learning. Enterprises should pay attention to the acquisition and absorption of management knowledge. Paying attention to and utilizing the knowledge of management and management, it is necessary for enterprises to innovate independently.

\section{Tacit Knowledge Elements}

Knowledge incentive. Knowledge motivation refers to the knowledge and skill needs that can motivate employees' innovative motivation. Enterprises use various effective methods to mobilize the enthusiasm and creativity of the employees, so that employees can adjust their knowledge structure by constantly identifying and absorbing the new knowledge in the external environment of the enterprise, forming knowledge sharing of the employees, encouraging the collision and innovation of knowledge, so as to constantly improve the adaptation to the external demand. The ability to control and enhance the ability to innovate in the future will ultimately achieve the goal of enterprise's overall level of independent innovation.

As the owner of the core knowledge, the creation of knowledge comes from the mutual communication between the employees. Only the employees can extract knowledge from the complex technical system which have a high degree of association with the independent innovation of the enterprise, and improve the knowledge constantly. Therefore, enterprises should constantly encourage new employees to create new knowledge to enhance their ability of independent innovation. Effective knowledge incentives meet the needs of the staff. Knowledge motivation is mainly reflected in staff growth, job autonomy and business achievement and matching wealth. Enterprises should form a relaxed, trusted and friendly working environment within the organization, create a good atmosphere to stimulate the knowledge and creativity of employees, promote mutual learning and knowledge sharing among employees, and then speed up the pace of independent innovation of the enterprise and shorten the development cycle of the product.

New technical knowledge. The new technology needed in the actual design, research and development or product manufacturing process can be called the new technology knowledge. The new technology knowledge needs to be absorbed and used effectively by the people who have a deep understanding of the enterprise's own technology. In an organization, new technical knowledge is often created not by a single individual, but on the basis of the shared knowledge and expertise of a team or group under the framework of the entire enterprise. New technological knowledge promotes the reconfiguration and integration of enterprises' innovative resources, and promotes the creativity of enterprises in an all-round way.

The new technology knowledge itself can not automatically create wealth. Only by constantly accumulating and applying it can the independent innovation ability of enterprises be improved. The formation of new technology knowledge must be based on a certain knowledge stock. Sufficient 
knowledge accumulation brings more knowledge to enterprises. The new technology knowledge has its own characteristics, and complexity, which make the new technical knowledge not easily obtained by other organizations. Therefore, in the process of enterprise independent innovation, it has greater use value than conventional technical knowledge. In addition, the dependence of new technology knowledge on the stock of enterprises is relatively high, which is mainly reflected in the path dependence of knowledge. If the stock knowledge of enterprises provides innovative resources, this advantage will continue with the emergence of new technological knowledge, forming a benign cycle.

Product development skills. Product development skills refers to the integration of internal and external knowledge resources, from the research and selection of products adapted to market needs, to product design and process design, and to a series of decision-making capabilities that have been put into normal production. Product development includes both the development of new products and the improvement and replacement of old products. Product development skill is an important skill of enterprise's independent innovation, and it is also the strategic core of enterprise's survival and development. In the process of developing new products, enterprises use knowledge to effectively allocate the limited resources to the urgent development projects, make the best effect of the new product development, and meet the diversification and individualized demand of the market.

Information processing capability. Information processing capability refers to the process that enterprises collect information from the false, retain the truth, eliminate the rough and extract the essence, and start from the outside to the inside. On the basis of the original information, the enterprise produces two activities of information activities that are of high value and convenient for customers to increase the value of information. Therefore, on the basis of certain information processing ability and proper processing of the original information, the enterprise can produce new information or knowledge to guide the independent innovation decision of the enterprise.

Under the traditional conditions, in the process of information and processing of enterprises, because of the unfriendly interface of the enterprise's own information system and the use of the information system, it makes the operation of the employees more tedious and brings psychological pressure to the employees, which affects the accuracy of the independent innovation decision of the enterprise. And the efficiency of decision making. Through the learning of the information system function and interactive mode, the enterprise can capture the information of the human-computer interaction interface in the short term. After the brain processing, it can be judged by the knowledge of the employees themselves and input into the information system for the information system processing. New support.

\section{References}

[1] Dosi, G. Technological Paradigms and Technological Trajectories: A Suggested Interpretation of the Determinants and Directions of Technical Change. Research Policy, 2012 (11):147-162.

[2] Johannes Sen and Jon-Aril. The future of value creation and innovations: Aspects of a theory of value creation and innovation in a global knowledge economy. International Journal of Information Management, 2009, 30(6): 502-511.

[3] Antony Satiates, mesh Maricopa, Nathalie P Coassignee .Knowledge Management Tutorial. Applications and reviews, 2011, 11(31):23-36.

[4] Peng L, Fang W. Heterogeneity of Inferring Reputation of Cooperative Behaviors for the Prisoners' Dilemma Game [J]. Physica A: Statistical Mechanics and its Applications, 2015, 433: 367-378. 